\title{
O ESTÁGIO E SEU PAPEL NA FORMAÇÃO DOCENTE PARA O ENSINO SUPERIOR DE QUÍMICA
}

Isabela Christo Gatti'

Andréia Francisco Afonso ${ }^{2}$

\begin{abstract}
RESUMO: O artigo relata trabalhos desenvolvidos ao longo do estágio de docência fixado como parte das atividades obrigatórias da pós-graduação, caso o aluno seja bolsista. O objetivo é analisar a aceitação de metodologias diferenciadas pelos estudantes da graduação e o papel do estágio na formação docente para o ensino superior. Ao longo do referido estágio foram realizadas atividades em sala de aula envolvendo leitura, utilização de modelos e fotografias. Foi mantido paralelamente um diário de bordo, no qual eram registradas nossas percepções sobre as atividades e sobre a formação para a docência no ensino superior. Também foi aplicado um questionário ao final do semestre para que os alunos opinassem sobre as atividades desenvolvidas. Ao final do estágio verificamos boa aceitação dos modelos e do uso de fotografias, não sendo tão fácil desenvolver processos de leitura naquele contexto. Assim, o percurso adotado nesse estágio de docência favoreceu o desenvolvimento de reflexões necessárias a uma formação para a atuação no ensino universitário, ao mesmo tempo em que estimulou o desenvolvimento de atividades diferenciadas na universidade.
\end{abstract}

Palavras-Chave: Ensino de Química; Estágio; Formação Docente.

ABSTRACT: The article reports activities developed during the Teaching Internship, set as part of the mandatory postgraduate activities, if the student is a scholarship holder. The objective is to analyze the acceptance of differentiated methodologies by undergraduate students and the role of the internship in teacher education for higher education. Throughout the internship, activities were carried out in the classroom involving reading, use of models and photographs. At the same time, a logbook was kept, in which our perceptions about the activities and the training for teaching in higher education were recorded. A questionnaire was also applied at the end of the semester for students to give their opinion on the activities developed. At the end of the internship, we verified good acceptance of the models and the use of photographs, it is not so easy to develop reading in that context. Thus, the course adopted in this Teaching Internship favored the development of reflections necessary for training to work in university education, while stimulating the development of different activities at the university.

Keywords: Teacher Education; Chemistry Teaching; Supervised Internship.

\section{Introdução}

Ainda que os parâmetros investigação, ciência, cultura, educação e ensino sejam constantes em qualquer instância da universidade, eles estão constantemente sob pressões externas e internas, em um equilíbrio bastante complexo e dinâmico de vários pontos de tensão que, permeados pelos momentos históricos, ajustam esses parâmetros às transformações sociais e aos redirecionamentos dos objetivos econômicos do país. Desde o surgimento até os entrelaces mais recentes, a própria história das universidades

\footnotetext{
${ }^{1}$ Mestre em Química e aluna de doutorado do Programa de Pós-Graduação em Química, Universidade Federal de Juiz de Fora/MG. Contato: isagatti.quimica@gmail.com

²Doutora em Ciências (UFSCar). Professora do Programa de Pós-Graduação em Química. Universidade Federal de Juiz de Fora/MG. Contato: andreia.afonso@ufjf.edu.br
} 
brasileiras as mantém nesse estado de rica complexidade que permite nutrir múltiplas possibilidades de pesquisa e ação para o ensino superior.

Portanto, quando pensamos no ensino universitário as possibilidades de discussão são múltiplas, passando desde as questões históricas e políticas até chegar à sala de aula e às práticas docentes ali exercidas. Obviamente, é impossível e improdutivo destacar qualquer prática de seu contexto mais amplo e, por isso, neste trabalho serão discutidas algumas metodologias de ensino que foram aplicadas durante um Estágio Docência em uma disciplina da graduação sem desconsiderar o campo da formação docente para o ensino universitário. Tais metodologias já foram exploradas pela pesquisa acadêmica, o que fornece subsídios para sua prática de forma embasada e em diálogo com as questões centrais da formação docente.

\section{Referencial teórico}

É no processo de democratização e expansão do ensino superior que os governos dos países em desenvolvimento vislumbram uma das possibilidades de ascensão econômica. Assim, novas políticas são formuladas sob a perspectiva de que a formação superior exerce papel fundamental no desenvolvimento de uma sociedade mais democrática, igualitária, instruída e profissionalmente capacitada. Essa estratégia, que no Brasil ganha maior expressividade com o Programa de Apoio a Planos de Reestruturação e Expansão das Universidades Federais (Reuni)3 (BORGES; AQUINO, 2012), é mobilizada por diversos países, mas apesar dos esforços e investimentos, a igualdade de acesso ao ensino superior não é realidade em nenhum deles (DUBET, 2015).

Inclusive, devido ao modo como ocorreu a institucionalização da universidade no Brasil, "[...] as demais instituições não-universitárias posicionam-se sempre, em certa medida, com relação a ela e podem, portanto, ser estudadas tomando-a como referência" (MENDONÇA, 2000, p. 132). Isto é bastante relevante se estivermos pensando nas práticas docentes universitárias, pois elas interferem de modo direto e significativo no que está posto para a educação básica e para as práticas profissionais no mercado do trabalho.

A expansão das Instituições de Ensino Superior (IES), ocorrida principalmente ao final do século XX e no início do XXI, é acompanhada de um aumento no número de cursos ofertados e no número de alunos, elevando também a demanda por professores (CONFORTIN, 2015). O Censo 2013 do Instituto Nacional de Pesquisas e Estudos Educacionais Anísio Teixeira (INEP) indicava uma diferença significativa entre a quantidade de professores das redes privada e pública. Enquanto a rede privada possuía 212.063 docentes, a rede pública contava com 155.219. Todos esses professores se relacionam diariamente com um quadro de alunos bastante diverso, sendo necessária uma prática

\footnotetext{
3 O Reuni é uma das ações que integram o Plano de Desenvolvimento da Educação (PDE) e foi instituído pelo Decreto n. 6.096, de 24 de abril de 2007.
} 
docente que se adeque ao contexto atual do ensino superior, permeado por grandes desafios quando se fala de formação de professores.

Diante dessa reconhecida necessidade, tomam forma muitas pesquisas, teóricas e empíricas, que se dedicam a compreender o papel do professor universitário, especialmente seus saberes e suas práticas. Embora as pesquisas empíricas ainda não estejam tão alavancadas quanto seria desejável, ambas já descrevem alguns problemas e algumas soluções para a formação e para a prática docente universitária mantendo vistas em uma capacitação que possa melhorar a qualidade do ensino nesse nível. Assim, para qualquer que seja o curso, é um consenso entre os pesquisadores da educação que a docência universitária deve ser repensada para formar, minimamente, cidadãos que exerçam sua profissão de modo ético, que sejam socialmente comprometidos e que estejam aptos a solucionar os problemas da sociedade contemporânea (FÁVERO; TONIETO, 2015).

Contudo, a quantidade de relatos sobre como esses problemas foram sanados ainda é escassa. Devido ao modo como se formam, os professores tendem a reproduzir o comportamento que apreenderam com seus próprios professores ao longo da trajetória escolar e acadêmica, resultando em uma prática não refletida e que perpetua os problemas ao invés de solucioná-los (ibidem). Joaquim, Boas e Carrieri (2012) corroboram com essa visão ao comentarem que, na docência universitária, os professores “[...] ensinam geralmente como foram ensinados, garantindo, pela sua prática, uma transmissão mais ou menos eficiente de saberes e uma socialização idêntica àquela de que eles próprios foram objeto" (p. 507).

É esse o movimento que leva à permanência das práticas tradicionais no ensino superior, baseadas em improvisos que não são frutos de um conjunto de habilidades e competências para a docência, mas sim, da crença de que saber o conteúdo seria suficiente para ensinar (FÁVERO; TONIETO, 2015; ibidem). É importante perceber que tal reprodução não só é incapaz de motivar os atuais alunos universitários, que têm perfis e interesses diversos, como é inundada de incoerência, pois quando alunos os professores certamente já proferiram ao menos uma vez as mesmas reclamações das quais agora são alvo.

O problema central da reprodução é a continuidade que ela cria para a visão da transmissão do conhecimento como concepção de ensino, dificultando que os aspectos pedagógicos da construção do conhecimento sejam o cerne do ensino superior. Dessa forma, a prática tradicional degrada a qualidade do ensino superior tão intensamente quanto for o nível de tradicionalismo adotado (ROJAS-BETANCUR, 2011). Trata-se de um problema que se fortalece em uma prática que não reflete sobre si mesma e, por essa razão, as soluções sugeridas pelos pesquisadores para melhorar a qualidade da formação superior recaem sobre dois aspectos principais: investir em formação continuada e incentivar e desenvolver uma prática reflexiva na universidade (SCHÖN, 1995; TARDIF, 
2000; CUNHA, 2006; BOLZAN; AUSTRIA; LENZ, 2010; ALMEIDA, 2016; FÁVERO; TONIETO, 2015; CONFORTIN, 2015; LEVINSKY; CORREA; MATTOS, 2015; JUNGES; BEHRENS, 2016;).

Essas posturas são tomadas porque é consensual entre os pesquisadores a posição que defende que o domínio do conteúdo, embora essencial, está longe de ser suficiente para a docência universitária no século XXI. Todavia, não há iniciativas legais para definir a formação pedagógica dos professores do ensino superior, sendo exigidos apenas os títulos de mestre, doutor ou especialista (ARANTES; GEBRAN, 2012). Ainda segundo o Censo 2013 do Inep, $39,7 \%$ dos professores das IES tem mestrado, 33\% tem doutorado, $24,8 \%$ tem especialização, e 2,4\% tem apenas a graduação. Isto é, aproximadamente $72 \%$ desses profissionais se formaram em programas stricto sensu que privilegiam a pesquisa, a imersão e a exploração profunda de um ponto específico de um dos campos do saber, não envolvendo a formação pedagógica que se considera imprescindível (BARONEZA; SILVA, 2007).

Decorre dessa prática uma importantíssima questão sobre a formação acadêmica nesses programas: em que medida ela contribui para a melhoria do ensino nas IES? De que modos ela modifica ou perpetua as práticas docentes que se baseiam na ideia de que para ser professor universitário basta ser um bom pesquisador e conhecer a fundo determinado assunto? Quais são as consequências de um ensino universitário no qual os docentes têm pouca ou nenhuma formação para a docência? (BASTOS et al., 2011).

De acordo com Tardif (2000; 2014), os saberes docentes são plurais e temporais, englobando muitos aspectos além do conhecimento do conteúdo e tendo diferentes origens: pessoais, da formação escolar anterior, da formação profissional, dos programas curriculares e dos livros didáticos, e da experiência na escola, na sala de aula e na profissão. Os professores mobilizam seus saberes de diferentes formas em diferentes contextos e situações para atingir variados objetivos, fazendo com que a docência permaneça em movimento. Contudo, no ensino superior nem sempre os professores têm consciência da existência desses saberes, o que os impede de racionalizá-los para melhor objetivá-los (CONFORTIN, 2015).

O Estágio de Docência é uma das atividades realizadas nos cursos de pós-graduação, no qual o aluno de mestrado ou doutorado bolsista exerce atividades de docência nas turmas sob supervisão de seu orientador, quando este leciona disciplinas na graduação. Esse estágio é obrigatório e regulamentado pela Coordenação de Aperfeiçoamento de Pessoal de Nível Superior (CAPES), sendo parte integrante da formação de mestres e doutores e visando o aprimoramento do ensino da graduação bem como uma melhor integração entre graduação e pós-graduação (FEITOSA, 2002).

Apesar de não ser tão valorizado quanto a pesquisa, a literatura aponta que o Estágio de Docência pode ser um espaço extremamente fértil para o desenvolvimento dos saberes docentes se for concedida ao aluno de pós-graduação a oportunidade de conduzir e coordenar atividades didáticas e se houver diálogo entre todas as partes envolvidas de 
modo que sejam proporcionados momentos de reflexão que enriqueçam a formação para a docência (PIMENTEL; MOTA; KIMURA, 2007; CAMPELO et al., 2010). Nesse sentido, o aluno da pós-graduação deve assumir uma postura ativa em seu Estágio de Docência e atuar na própria formação de forma significativa, orientada e reflexiva, pois assim conseguirá desenvolver sua docência de modo que se torne capaz de:

[...] reconhecer a intencionalidade pedagógica que orienta suas ações e valorizar o protagonismo dos alunos, sem desconsiderar seus interesses e curiosidades, ao mesmo tempo em que fornece os meios para a conquista das competências esperadas pela disciplina (WALL; PRADO; CARRARO, 2008, p. 518).

Pesquisando um grupo de professores do curso de Pedagogia em um contexto de formação continuada, Arantes e Gebran (2015) relataram alguns problemas centrais para a docência no ensino universitário, como a predominância de aulas expositivas, a falta de aprendizagem sobre a docência com os pares e a concepção de teoria e prática como aspectos dissociados da profissão. Esses problemas permeiam todos os cursos e é um grande desafio solucioná-los, especialmente por estar o professor no centro deles, podendo se traduzir em infértil atribuição de culpas a esses sujeitos.

É por essa razão que espaços de formação, como o Estágio de Docência e também a formação continuada, não só contribuem para a formação do professor reflexivo, que faz o processo de ação-reflexão-ação e de reflexão-na-ação proposto por Schön (1995), mas também alimentam a construção de saberes docentes que permearão a prática futura. Não se trata de abandonar o que já se sabe, mas sim de repensar, refletir e ressignificar os saberes, compreendendo o que se sabe e o que não se sabe para então mudar a prática de modo objetivo e esclarecido, em oposição ao jogo de tentativa e erro resultante de uma prática não refletida que pouco contribui para uma democratização do ensino superior que resulte, de fato, em desenvolvimento para o país (CONFORTIN, 2015).

\section{Metodologia}

No Programa de Pós-Graduação em Química (PPGQ) da Universidade Federal de Juiz de Fora, o Estágio de Docência é uma das atividades obrigatórias para os alunos de mestrado e doutorado. Essa pesquisa foi realizada no primeiro semestre de 2016, durante o referido estágio, cursado durante o mestrado da primeira autora do presente trabalho, sendo a segunda autora a professora orientadora e regente da turma. Durante essa experiência foi acompanhada uma das turmas da disciplina Química Fundamental, oferecida pelo Departamento de Química aos cursos de graduação.

Havia 63 estudantes na turma, estando eles matriculados nos seguintes cursos: Licenciatura em Química (1), Ciências Exatas (4) e Engenharias (58). Portanto, a turma era composta majoritariamente por estudantes de Engenharia que cursaram a disciplina Química Fundamental no segundo semestre de seu currículo. 
No geral, os alunos foram bem aplicados e atenderam às aulas com frequência satisfatória. A ementa ${ }^{4}$ da disciplina abrange os conteúdos de estrutura atômica, classificação periódica, ligações químicas, introdução às funções e reações químicas. 0 cronograma é estabelecido pelos docentes antes do início das aulas, devendo ser mínimas as modificações ao longo do semestre, pois as avaliações são as mesmas para todas as turmas do mesmo período letivo (manhã, tarde e noite).

Ao longo do semestre foi mantido um Diário de Bordo, no qual a estagiária fazia registros sobre as aulas e reflexões sobre sua formação para a docência. As inscrições no diário foram feitas a cada aula (duas vezes por semana) com um tempo máximo de dois dias entre a aula e o registro. O diário completo foi enviado à professora regente da disciplina para complementar as discussões que aconteceram ao longo do semestre entre professora e estagiária.

Na última aula da disciplina foi aplicado um questionário ${ }^{5}$ junto aos estudantes. $\mathrm{O}$ objetivo foi obtermos dados para analisarmos a aceitação das metodologias de ensino utilizadas naquele semestre e a intensidade com que eles perceberam a construção dos seus conhecimentos durante a disciplina. Para cada tipo de aula do semestre foi solicitado que os alunos assinalassem se participaram ou não da aula e os itens que consideraram que a aula os ajudou, podendo assinalar mais de um item dentre os seguintes: resolução de exercícios; resolução da prova; compreensão dos conceitos; e contextualização do conteúdo. Para cada tipo de aula foi deixado um espaço em branco no questionário para que eles pudessem fazer um comentário sobre as propostas, caso desejassem.

Nesse contexto, a professora concedeu a escolha de três aulas para a regência e esteve disponível para discutir o conteúdo e o planejamento sempre que solicitada. As três aulas escolhidas foram: introdução à mecânica quântica e geometria molecular (duas aulas). Além dessas três aulas, também foi realizada uma intervenção com uma atividade avaliativa na aula cujo tema era interações intermoleculares. As demais aulas do semestre foram expositivas, em sua maior parte acompanhadas de resolução de exercícios ao longo da aula ou ao final da mesma.

Na Tabela 1 estão dispostos os temas e os conceitos que foram trabalhados em cada aula pela estagiária:

\footnotetext{
${ }^{4} \mathrm{~A}$ ementa da disciplina pode ser consultada no endereço http://www.ufjf.br/quimica/disciplinasdep/planode-ensino/?CodDisciplina=QU1125.

${ }^{5}$ Os alunos que responderam ao questionário assinaram um Termo de Consentimento Livre e Esclarecido (TCLE), autorizando o uso das respostas para fins de pesquisa e garantindo o anonimato de cada participante.
} 
- Revista de Iniciação à Docência, v. 5, n. 2, 2020 -

Publicação: agosto, 2020 - ISSN 2525-4332

Tabela 1. Aula, tema e conceitos trabalhados.

\begin{tabular}{|l|l|l|}
\hline $\begin{array}{l}\text { POSIÇÃO DA AULA } \\
\text { NO CRONOGRAMA }\end{array}$ & \multicolumn{1}{|c|}{ TEMA } & \multicolumn{1}{|c|}{ CONCEITOS TRABALHADOS } \\
\hline Aula 7 & Átomos polieletrônicos & $\begin{array}{l}\text { Orbitais e energia; spin eletrônico; Princípio da Exclusão de Pauli; } \\
\text { configurações eletrônicas; Regra de Hund. }\end{array}$ \\
\hline Aula 15 & $\begin{array}{l}\text { Geometria molecular } \\
\text { (parte 1) }\end{array}$ & $\begin{array}{l}\text { Repulsão dos Pares Eletrônicos no Nível de Valência para moléculas } \\
\text { com e sem pares de elétrons isolados no átomo central. }\end{array}$ \\
\hline Aula 16 & $\begin{array}{l}\text { Geometria molecular } \\
\text { (parte 2) }\end{array}$ & $\begin{array}{l}\text { Efeito dos elétrons não ligantes e das ligações múltiplas nos ângulos } \\
\text { de ligação. }\end{array}$ \\
\hline Aula 22 & $\begin{array}{l}\text { Interações } \\
\text { intermoleculares }\end{array}$ & $\begin{array}{l}\text { Origem das forças intermoleculares; Forças íon-dipolo, dipolo- } \\
\text { dipolo, dispersão de London e ligação de hidrogênio; Relação } \\
\text { entre propriedades físicas e interações intermoleculares. }\end{array}$ \\
\hline
\end{tabular}

Fonte: Elaborado pelas autoras.

\section{1 - Aula 7: Um exercício de leitura}

Devido à natureza abstrata dos conteúdos da aula de introdução à mecânica quântica, existe uma dificuldade em explorar metodologias que fogem da tradicional. Assim, o tema foi trabalhado de forma dialógica para que os conceitos pudessem ser discutidos com os estudantes e não apenas apresentado a eles. Foi inserido um trecho do livro Alice no País do Quantum (Figura 1) para um exercício de leitura e interpretação sobre o Princípio da Exclusão de Pauli:

Figura 1. Trecho do livro Alice no País do Quantum, utilizado na aula 7.
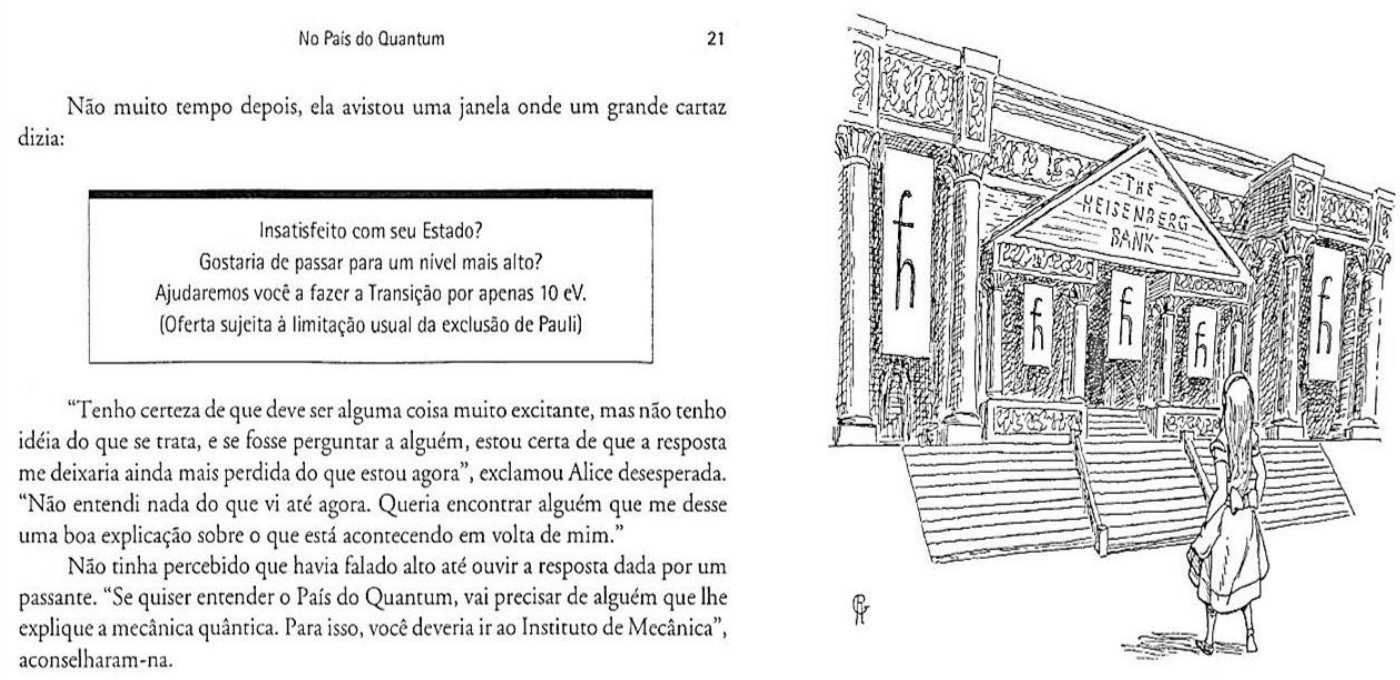

Fonte: Acervo das autoras. 
Esse trecho do livro foi posicionado logo após a explicação acerca do que é spin eletrônico e o do Princípio da Exclusão de Pauli. Foi explicado o contexto do livro: trata-se de uma alegoria na qual a personagem Alice explora o mundo da física quântica se tornando tão pequena quanto os elétrons. O livro é uma introdução ilustrada à Física Quântica que busca tornar acessíveis ao leitor os aspectos essenciais desse ramo da Física. O livro não se aprofunda nas equações, embora faça comentários sobre as mais relevantes.

É comum que as aulas de Química se concentrem nos aspectos quantitativos em detrimento dos qualitativos, como a leitura, a escrita e a criatividade (FLÔR, 2009; QUEIROZ, 2001). Contudo, nessa disciplina tão inicial não cabe explorar a física quântica de modo quantitativo. Ainda assim, os alunos precisam compreender alguns conceitos quânticos para prosseguir na disciplina. Além disso, atualmente exige-se muito mais do que habilidades de resolução de cálculos dos profissionais da ciência. A opção por integrar, ainda que brevemente, a literatura em uma aula de Química é uma escolha pela interdisciplinaridade e pretende explorar as fronteiras entre essas disciplinas, forçando os limites da concepção socialmente arraigada de que literatura e ciência são vertentes opostas do conhecimento (JAPIASSU, 1976).

Dessa forma, a leitura conjunta das páginas mostradas na Figura 1 foi usada para impulsionar questões acerca da estrutura de átomos polieletrônicos focando no seguinte fragmento: "oferta sujeita à limitação usual da exclusão de Pauli". Foi realizado, portanto, um exercício de leitura e interpretação de texto, pois foi perguntado aos alunos qual o sentido desse fragmento dentro do contexto da mudança de Estado do elétron.

\section{2 - Aulas 15 e 16: Trabalhando com geometrias moleculares e modelos}

Enquanto a aula 15 ficou reservada ao estudo e para a discussão dos conceitos, na aula 16 foi realizada uma atividade em grupo. Na primeira aula, foram levados balões de festa e modelos de acrílico para auxiliar na visualização tridimensional das geometrias moleculares, deixando que os estudantes manuseassem os modelos. A atividade em grupo proposta na segunda aula foi o preenchimento de uma tabela, colada em cartolina, com as seguintes informações sobre 15 moléculas: estrutura de Lewis; quantidade total de domínios ligantes e não ligantes; nome do arranjo e da geometria molecular; desenho da geometria molecular; ângulos de ligação; polaridade das ligações e das moléculas.

Visto que o preenchimento da tabela demandaria bastante tempo, dedicamos a $2^{\mathrm{a}}$ aula inteira para a atividade. Foram fornecidos modelos plásticos de bola e bastão para montar as estruturas moleculares (Figura 2) e modelos de papel para serem colados (Figura 3). 
Figura 2. Modelos plásticos.

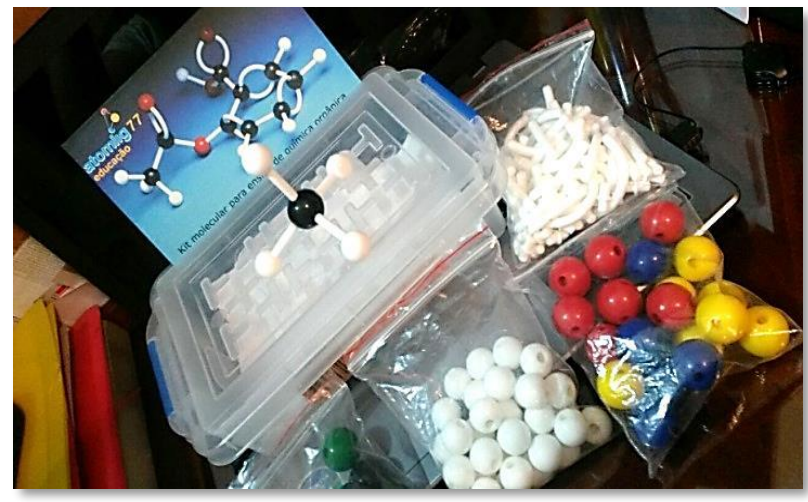

Fonte: Acervo das autoras.
Figura 3. Modelos de papel: a) tetraedro;

b) octaedro; c) bipirâmide. (Fonte: Google imagens)

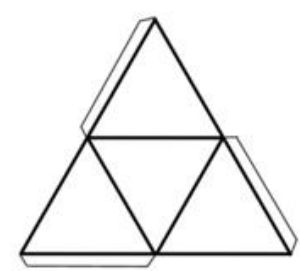

a)

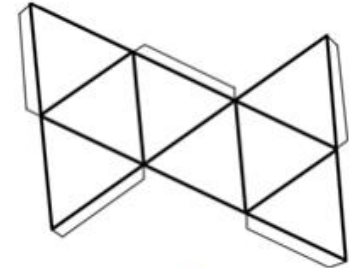

b)

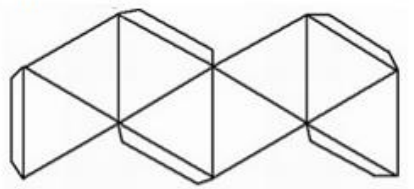

Fonte: Google imagens.

O uso de modelos é uma metodologia de ensino bastante explorada na literatura e recomendada para o ensino de Química porque ajuda os estudantes a fazerem a transição entre os níveis macroscópico, submicroscópico e representacional, facilitando a compreensão da matéria na escala molecular e como isso se relaciona com as propriedades observáveis (WARTHA; REZENDE, 2011). Ao trabalhar com modelos a parcela abstrata e/ou não observável é tomada como observável por comparação. É preciso deixar claro que as moléculas não são iguais aos modelos assim como um edifício não é igual à sua maquete, mas sim que cada parte do modelo representa um aspecto da realidade. Assim, o modelo é uma representação da realidade e não a realidade em si, tendo sua utilidade maior ao nos aproximar a uma realidade inacessível para então melhor compreendê-la (FERREIRA; JUSTI, 2008; FRANCISCO JR., 2008; RAUPP; SERRANO; MOREIRA, 2009; SOLAZ-PORTOLÉS, 2012; MELO; LIMA NETO, 2013).

\section{3 - Aula 22: Avaliação com fotografias}

Na aula 22 aplicamos uma avaliação extra na qual os alunos deveriam nos enviar uma fotografia de sua autoria que, em sua perspectiva, fosse capaz de representar ao menos uma das interações intermoleculares. As fotografias enviadas foram organizadas em um arquivo de PowerPoint e apresentadas à turma em uma das aulas. A apresentação se caracterizou como um momento de discussão e revisão do assunto abordado.

Na educação, as fotografias mobilizam a curiosidade e a sensibilização gerada pelas imagens (BORGES; ARANHA; SABINO, 2010). Como recurso avaliativo, a fotografia pretende não só estimular o aluno a perceber a ciência no seu dia a dia, mas também facilitar a aproximação do professor com a realidade do aluno bem como as interações professor-aluno e aluno-aluno durante a apresentação das fotografias (ALMEIDA, 2016). 
Foi solicitado que os alunos escrevessem um pequeno texto (máximo de 10 linhas) com uma breve explicação sobre a relação entre a imagem e o fenômeno, pois:

o sentido do discurso emerge não só da significação usual, denotada e transparente da forma, mas, sobretudo, dos implícitos que circulam entre o uso da forma em diferentes contextos sociocomunicativos e, principalmente, da identidade dos sujeitos e das intenções dos mesmos para com o ato de linguagem (MONFORTE, 2018, p.469).

Assim, o conjunto imagem-texto é útil para melhor embasar a avaliação, uma vez que os alunos devem mobilizar seus conhecimentos e linguagem científica para elaborar uma explicação para a escolha daquela imagem.

\section{Resultados e Discussão}

Pensando no Estágio de Docência como processo de formação para atuação no ensino superior, escrever o diário foi muito significativo, principalmente por não haver espaço destinado à reflexão junto a outros estudantes de pós-graduação. Acreditamos que, mesmo que isso não seja um impedimento à reflexão contínua, é necessário incentivar a criação de tal espaço, por proporcionar um ambiente de problematização da docência no ensino superior sob uma perspectiva crítica e fomentar o compartilhamento de ideias e ideais positivos para a educação (ARROIO, 2009). Tal criação poderia ajudar a construir uma formação docente menos solitária na busca pela "superação das contradições e limitações da prática docente no ensino superior, uma vez que as ações educam mais que os discursos" (ibidem, p. 10).

Reservar o momento da escrita para elaborar as ideias sobre as vivências no estágio permitiu emergir aspectos subjetivos sobre a experimentação da docência. Também possibilitou questionar e tomar consciência de aspectos que não vem à tona em outros momentos, o que também é passível de acontecer em espaços de reflexão com outros estudantes. Nesse sentido, podemos pensar na manutenção do diário como uma escrita que "[...] funciona como "invenção de si", na medida em que possibilita construir e reconstruir acontecimentos, ideias, memórias, imagens representações, um dispositivo que produz processos de subjetivação, [...] possibilitando novos modos de existência" (CASTRO, 2016, p. 7).

Dos 63 alunos $^{6}$ matriculados na disciplina, 47 responderam ao questionário e assinaram o TCLE. O questionário não só serviu como ferramenta de pesquisa, mas também criou um espaço no qual os estudantes puderam expressar como perceberam as aulas desenvolvidas. Isso complexifica o nível de participação dos alunos no próprio processo educativo, pois eles podem opinar sobre o processo do qual participam. Os itens assinalados pelos alunos foram quantificados e estão expostos na Tabela 2:

\footnotetext{
${ }^{6}$ Para preservar a identidade dos estudantes, atribuímos numeração aleatória de E1 a E19 para aqueles que fizeram comentários no questionário (total de 19 estudantes).
} 
- Revista de Iniciação à Docência, v. 5, n. 2, 2020 -

Publicação: agosto, 2020 - ISSN 2525-4332

Tabela 2. Dados dos questionários respondidos pelos alunos.

\begin{tabular}{|l|c|c|c|c|}
\hline $\begin{array}{l}\text { AULAS EXPOSITIVAS COM } \\
\text { RESOLUÇÃO DE EXERCÍCIOS }\end{array}$ & $\begin{array}{c}\text { RESOLUČ̃̃O DE } \\
\text { EXERCíCIOS }\end{array}$ & $\begin{array}{c}\text { RESOLUÇÃO } \\
\text { DA PROVA }\end{array}$ & $\begin{array}{c}\text { COMPREENSÃO } \\
\text { DOS CONCEITOS }\end{array}$ & $\begin{array}{c}\text { CONTEXTUALIZAÇÃO } \\
\text { DO CONTEÚDO }\end{array}$ \\
\hline $\begin{array}{l}\text { AULAS EXPOSITIVAS } \\
\text { SEM RESOLUÇÃO DE } \\
\text { EXERCÍCIOS }\end{array}$ & $\begin{array}{c}29 \\
(67,9 \%)\end{array}$ & $\begin{array}{c}35 \\
(61,7 \%)\end{array}$ & $\begin{array}{c}22 \\
(74,5 \%)\end{array}$ & $(46,8 \%)$ \\
\hline AULA 7 & $(21,3 \%)$ & $(19,1 \%)$ & $\begin{array}{c}37 \\
(78,7 \%)\end{array}$ & $\begin{array}{c}24 \\
(51,1 \%)\end{array}$ \\
\hline AULA 15 & 9 & 5 & 21 & 22 \\
$(19,1 \%)$ & $(10,6 \%)$ & $(44,7 \%)$ & $(46,8 \%)$ \\
\hline AULA 16 & 21 & 16 & 31 & 26 \\
& $(44,7 \%)$ & $(34,0 \%)$ & $(66,0 \%)$ & $(55,3 \%)$ \\
\hline AULA 22 & 23 & $\begin{array}{c}17 \\
(36,2 \%)\end{array}$ & $\begin{array}{c}26 \\
(55,3 \%)\end{array}$ & $\begin{array}{c}17 \\
(36,2 \%)\end{array}$ \\
\hline
\end{tabular}

Fonte: Elaborado pelas autoras.

De acordo com os dados da Tabela 2 e com os comentários dos participantes, as aulas com maior potencial para ajudar na resolução dos exercícios e da prova foram as expositivas com resolução de exercícios. Isso mostra que na percepção desses estudantes, a aula que mais se aproxima da tradicional é aquela que melhor prepara-os para as avaliações (também tradicionais), como fica evidenciado nos seguintes comentários:

Considero que a resolução de exercícios é de extrema importância para o aprendizado, principalmente quando se trata de uma ciência exata. (E6)

A resolução de exercícios é fundamental para aplicar os conceitos, qualificando o ensino. (E10)

Ajudou muito na hora de fazer a prova! (E12)

Contudo, existe uma concepção errônea derivada da prática constante (quando não exclusiva) de aulas expositivas: alguns alunos concebem a resolução de exercícios teóricos como uma aplicação do conhecimento adquirido na aula, o que pode ser observado nos seguintes comentários:

Essencial para a compreensão do conteúdo e para trazer para o nosso meio as aplicações, como dito acima, mas sugiro realizar essas aulas com um exercício final para aplicarmos na prática a exposição teórica. (E4, grifo nosso)

Porém as aulas com resolução foram mais úteis para me preparar para a prova e fixar o conceito. $A$ compreensão dos conceitos nestas aulas foi algo mais geral e menos prático. Sem dúvida importante, mas eu sinto que a resolução e comentários de exercícios me ajudou mais, grosseiramente falando. (E19, grifo nosso)

Ao tomarem a resolução de uma questão proposta em livro, cujo objetivo seria exercitar o pensamento lógico e a interpretação de possíveis situações, como a parte prática do conhecimento aprendido em sala de aula, os alunos expõem a força do tradicionalismo na educação brasileira, na qual o objetivo final de estudar é se preparar e 
fazer as avaliações. Com efeito, estuda-se para provar que se sabe algo a alguém que sabe mais e transfere esse conhecimento aos que ainda não sabem. Nesse sentido, a reprodução é tida como um tipo de prática do conhecimento.

Apesar da coerência entre metodologia adotada e a avaliação ser algo desejável, esses comentários ressaltam o quanto a avaliação universitária pode ser tão (ou mais) rígida e tradicional quanto a escolar. Essa visão é absolutamente incoerente com a contemporaneidade, na qual os problemas complexos exigem cada vez mais habilidades criativas e múltiplas dos profissionais egressos das universidades (FÁVERO; TONIETO, 2015). As respostas em branco dos mesmos 47 questionários estão dispostas na Tabela 3:

Tabela 3. Dados das respostas em branco nos questionários respondidos pelos alunos.

\begin{tabular}{|l|c|c|}
\hline & $\begin{array}{c}\text { BRANCO } \\
\text { (PARTICIPOU DA AULA) }\end{array}$ & $\begin{array}{c}\text { BRANCO } \\
\text { (NÃO PARTICIPOU DA AULA) }\end{array}$ \\
\hline AULAS EXPOSITIVAS & 0 & 0 \\
COM RESOLUÇÃO DE EXERCícIOS & $(0 \%)$ & $(0 \%)$ \\
\hline AULAS EXPOSITIVAS & 1 & 4 \\
SEM RESOLUÇÃO DE EXERCícIOS & $(2,1 \%)$ & $(8,5 \%)$ \\
\hline \multirow{2}{*}{ AULA 7 } & 0 & 11 \\
& $(0 \%)$ & $(23,4 \%)$ \\
\hline AULA 15 & 1 & 9 \\
& $(2,1 \%)$ & $(19,1 \%)$ \\
AULA 16 & 1 & 15 \\
& $(2,1 \%)$ & $(31,9 \%)$ \\
\hline \multirow{2}{*}{ AULA 22 } & 0 & 14 \\
& $(0 \%)$ & $(29,8 \%)$ \\
\hline
\end{tabular}

Fonte: Elaborado pelas autoras.

O maior número de respostas em branco corresponde à ausência de parte dos alunos na aula, sendo pequena a quantidade de alunos que participou da aula, deixando todos os itens em branco (máximo 2,1\%). Isso significa que, no máximo, um aluno ou aluna considerou que as aulas expositivas sem resolução de exercícios, bem como as aulas 15,16 e 22, não ajudaram quaisquer dos aspectos listados no questionário.

Um dos participantes fez o seguinte comentário sobre as aulas 15 e 16: "O tempo empregado na atividade pode ser melhor aproveitado na aula expositiva" (E3). Esse comentário, embora pontual, reforça a existência da perspectiva tradicional e utilitária na universidade. O referido participante encara as metodologias não tradicionais como um mau aproveitamento do tempo porque, afinal, se a avaliação da disciplina é elaborada em um modelo no qual o aluno precisa reproduzir o que foi ensinado em sala de aula, qual a função e a utilidade de uma aula que não faça exatamente isso?

Assim, ao invés de valorizar outras metodologias o aluno tende a se opor a elas, pois, em sua percepção, elas não o ajudam a avançar dentro do modelo acadêmico vigente. É esse tipo de resistência que o professor encontrará ao propor metodologias diferenciadas na universidade. De fato, 
- Revista de Iniciação à Docência, v. 5, n. 2, 2020 -

Publicação: agosto, 2020 - ISSN 2525-4332

a implementação de metodologias ativas em cursos de graduação implica no enfrentamento de múltiplos desafios, desde os estruturais (organização acadêmica e administrativa das instituições e cursos) até os de concepções pedagógicas (crenças, valores e modos de fazer) dos professores e alunos. (WALL; PRADO; CARRARO, 2008, p. 516).

Os estudantes universitários não esperam que a metodologia de ensino seja variada na universidade, pois essa não é a cultura com a qual estão habituados. É natural que isso aconteça, uma vez que os alunos são formados durante toda a sua vida escolar sob uma lógica tradicional.

O objetivo das aulas 7, 15, 16 e 22, de fato, não estava vinculado à preparação dos discentes para a prova escrita tradicional, mas sim, ajudá-los a compreender os conceitos, contextualizar os conteúdos, exercitar as linguagens e facilitar as interações em sala de aula. Como pode ser verificado na Tabela 2, a porcentagem de alunos que considerou que as aulas 7 e 22 auxiliaram nesses aspectos é maior do que a porcentagem que acredita ter ajudado na resolução de questões, portanto, consideramos que os objetivos dessas aulas foram satisfatoriamente atingidos. Sobre a aula 7, os comentários dos participantes foram os seguintes:

A aula não teve um teor formal tão grande, mas possibilitou o início do pensamento do funcionamento quântico. (E1)

Com temas mais abstratos, o uso de materiais alternativos é um mecanismo auxiliar eficaz no ensino. (E10)

Essa aula foi muito interessante. Fiquei com vontade de comprar o livro. (E16)

O conteúdo relativo à Geometria Molecular também facilitou a proposição de metodologias que contrastam com a tradicional - tão arraigada no nosso ensino superior e que se opõe ao despertar do interesse sendo, para muitos alunos, desencorajadora do estudo da Química e de suas aplicações (FEITOSA, 2002). A abordagem proporcionou uma fértil interação dialógica, pois foram feitas perguntas ao longo de toda a aula. Sobre a aula 15 os participantes comentaram que:

Uma das melhores aulas de contextualização do conteúdo, pois possibilitou a visualização em três dimensões das geometrias, o que não é tão comum em outros meios de estudo. (E1)

Aula essencial para o entendimento da matéria geometria molecular, ajuda a visualizar as geometrias e "memorizar" as mesmas. (E4)

Foi bem útil, para compreender melhor a forma dos orbitais. (E7)

Entendemos que “[...] um modelo não é uma cópia da realidade, muito menos a verdade em si, mas uma forma de representá-la originada a partir de interpretações pessoais desta" (FERREIRA; JUSTI, 2008, p. 32). Sob essa perspectiva, a construção foi proposta por ter potencial para discutir os modelos como representações de mundo, percepção essa que consideramos central para o ensino da Química. Essa questão não é 
muito debatida com os estudantes, levando muitos deles a se formarem sem tal compreensão.

A segunda aula (aula 16) desse tema também foi bastante profícua, pois estimulou o diálogo e o debate entre os alunos, aspecto bastante valorizado por eles:

\section{Possibilidade de discussão em grupo (foi positivo). (E1)}

O contato com o companheiro ajudou na compreensão como um "todo". (E2)

Atividade super dinâmica, em grupo, discutimos até chegar em uma única resposta. (E5)

Para mim, foi a aula que mais foi útil para a prova, fundamental para entender o conteúdo. (E8)

O empenho dos estudantes foi bastante satisfatório, o que foi possível perceber pela intensa movimentação da professora e da estagiária durante a aula, na qual os alunos as chamaram para ajudar com as estruturas e dialogar sobre o material e sobre o conteúdo. Isso é muito interessante para o Estágio de Docência, pois:

A educação de adultos que acontece nas universidades pressupõe a utilização de metodologias ativas de ensino e aprendizagem, que proponham desafios concretos a serem superados pelos acadêmicos, permitindo que eles sejam sujeitos na construção do conhecimento (WALL; PRADO; CARRARO, 2008, p. 516).

Nos livros didáticos, além de ilustrar, as fotografias são comumente utilizadas para despertar o interesse dos discentes e para tornar a leitura mais agradável ao serem intercaladas ao texto verbal, porém, pouco se trabalha com os discentes assumindo a posição de fotógrafos durante os processos de ensino-aprendizagem. Apesar de estarem presentes apenas 33 estudantes em sala no dia em que a proposta foi feita, 35 e-mails foram enviados com as fotos e as explicações solicitadas. Tivemos uma boa variedade de imagens, o que contribuiu muito para a discussão realizada na aula seguinte. As Figuras 4, 5 e 6 ilustram alguns exemplos das fotos enviadas pelos estudantes acompanhadas dos textos redigidos por eles para explicar a relação entre a imagem e a interação intermolecular observada:

Figura 4. Fotografia enviada para a atividade avaliativa da aula 22.

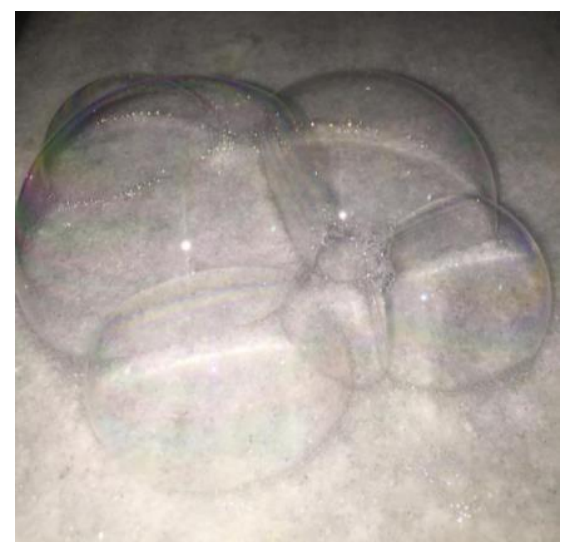

Escolhi essa foto para ser uma representação de interações intermoleculares porque as bolhas só existem pela força intermolecular presente nas moléculas de água (a ligação de hidrogênio) na superfície do sabão.

Fonte: Acervo das autoras. 
- Revista de Iniciação à Docência, v. 5, n. 2, 2020 -

Publicação: agosto, 2020 - ISSN 2525-4332

Figura 5. Fotografia enviada para a atividade avaliativa da aula 22.

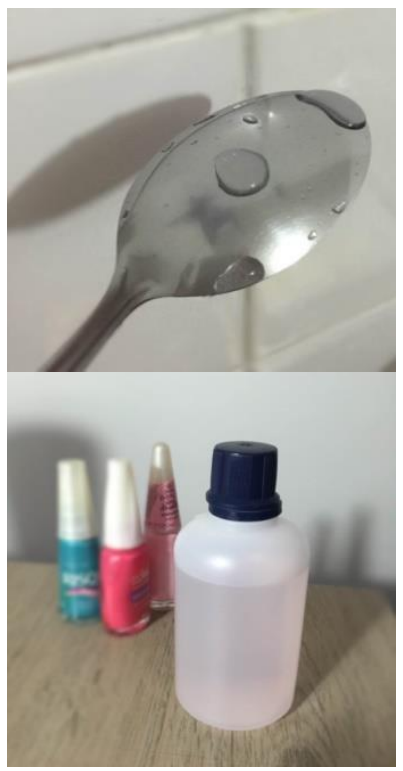

Li um pouco a respeito das interações intermoleculares e estou te enviando duas imagens. A primeira é uma colher com sentido invertido com algumas gotas de água sobre ela. As moléculas de $\mathrm{H}_{2} \mathrm{O}$ ficam agrupadas através de uma alta força intermolecular, fazendo com que fiquem em gotas e permitindo até que insetos caminhem sobre a água. Já que a água possui uma grande força intermolecular, ela possui relativamente um alto ponto de ebulição. Situação contrária à da acetona (segunda imagem), que por possuir forças intermoleculares de baixa intensidade, possui baixa temperatura de ebulição e é bem volátil.

Fonte: Acervo das autoras.

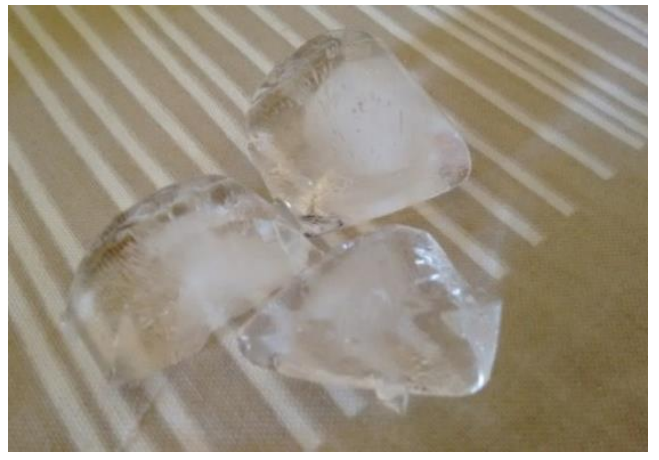

Tirei uma foto de cubos de gelo, que são formados por ligação de hidrogênio. Essa força intermolecular é bastante forte, sendo necessária uma energia bem alta para rompê-la. No exemplo que usei, a ligação de hidrogênio inclusive explica o fato do gelo flutuar na água. Já que as moléculas de hidrogênio ficam mais espaçadas criando uma zona hexagonal no centro do gelo (tentei cortá-lo ao meio para mostrar melhor, mas sei lá... não apareceu muito hahaha), seu volume fica maior, diminuindo sua densidade. Achei legal a ideia de usar esse exemplo, por poder associar uma interação intermolecular com esse fator externo (gelo boiando na água), que foi uma consequência da ligação de hidrogênio.

Fonte: Acervo das autoras.

Durante a apresentação das fotografias em aula o diálogo foi intenso, fomentando perguntas e curiosidades sobre as interações intermoleculares. Através das explicações elaboradas pelos alunos foi possível notar o empenho deles na atividade que, mesmo sendo relativamente simples, colocou-os em posição ativa frente ao conhecimento e ao cotidiano. Os alunos apresentaram sua associação do fenômeno com a fotografia de forma coerente e embasada, embora alguns tenham entregado cópias de trechos de livros ou texto muito sucintos.

O interessante dessa atividade avaliativa foi possibilitar que, através de fotografias de autoria dos próprios alunos, eles associassem seu conhecimento à realidade que os cerca, bem como se expressassem em primeira pessoa e de modo informal sobre o assunto sem deixar de utilizar a linguagem científica. Uma vez que o aluno precisa explicar, em 
primeira pessoa, como pensa a relação daquela imagem com as interações intermoleculares, ocorreu uma maior aproximação dos estudantes com o conteúdo da aula, o que contribuiu para que eles se apropriassem daquele conhecimento.

Foi estimulante estudar e buscar uma orientação metodológica diferente da habitual e ter a oportunidade de colocá-la em prática no ensino superior e descobrir como ela funciona em sala de aula, pois alimenta a busca pelas propostas de novas metodologias educativas que possam ser aplicadas no ensino universitário. Sobre a aula 22 os alunos fizeram os seguintes comentários:

Acho que este tipo de atividade pode ser incentivada, uma vez que nos leva a pensar na química em situações cotidianas. (E1)

Tive que pesquisar para realizar a atividade, o que me ajudou a contextualizar. (E7)

A foto despertou a curiosidade por saber os tipos de interação que estão ao meu redor. (E9)

Ajudou a entender o conteúdo, pois forçou-me a pensar na ocorrência de interações intermoleculares no dia a dia. (E17)

Melhor atividade, pois nos mostrou onde se aplica tais conceitos entretanto sobre as perguntas na prova não ajuda numa resposta direta. (E2)

Os comentários dos participantes que responderam aos questionários e a vivência do Estágio de Docência nos permitem afirmar que existe uma boa aceitação das metodologias não tradicionais no ensino superior de Química, ainda que a turma, em sua maioria, não estivesse cursando a graduação em Química.

A nosso ver, apesar de resistências pontuais, sempre é produtivo investir em metodologias não tradicionais, pois embora essa concepção seja bastante arraigada, esse esforço nos permite "[...] ajudar nossos alunos a irem se libertando de valores e crenças que os prendiam, impossibilitando-os de desenvolverem-se enquanto seres humanos" (WALL; PRADO; CARRARO, 2008, p. 518) desintegrando, aos poucos, a situação de dependência do sistema tradicional.

\section{Considerações finais}

A metodologia adotada durante o Estágio de Docência cumpriu seu propósito e, conforme apontam os resultados aqui apresentados, contribuiu para a construção dos conceitos e para a contextualização do conteúdo abordado na disciplina. Entretanto, ainda é necessário criar espaços para propor outras formas de avaliação que não a tradicional nos cursos de graduação, especialmente no que se refere às Ciências Exatas. A manutenção da prática docente tradicional não mais interessa à universidade, uma vez que o objetivo da formação ali proporcionada não é a reprodução de conhecimento, mas sim a utilização racional e criativa do mesmo para a resolução dos problemas contemporâneos.

Nesse sentido, buscar outras formas de ensino-aprendizagem da Química proporciona articular intencionalmente "a interação entre o conhecimento específico e o 
pedagógico, construindo a identidade profissional do futuro professor, rompendo com o modelo tradicional reproduzido em geral" (ARROIO, 2009, p. 9). Dessa forma, o Estágio de Docência pode se constituir como excelente ambiente formador para os alunos da pósgraduação strictu sensu, pois se trata de um espaço e um momento de praticar o que se aprendeu na Licenciatura, propor novas abordagens, bem como de questionar o ensino superior e os desafios enfrentados por esse setor da educação.

O acesso às opiniões dos alunos teve grande valor, pois fomentou ainda mais nossas reflexões acerca das metodologias do ensino de Química e a respeito do ensino universitário como um todo. Os resultados nos permitem inferir que o Estágio de Docência, se explorado de modo que o aluno de pós-graduação esteja à frente da condução e coordenação das metodologias de ensino, supervisionado por um orientador disposto a dialogar e refletir conjuntamente sobre as questões da docência, certamente contribuirá enormemente para o avanço no enfrentamento dos problemas atuais acerca da prática docente no ensino superior rumo a uma universidade mais capacitada para formar profissionais cada vez mais competentes para atuar no mundo contemporâneo.

\section{Referências}

ALMEIDA, B. A fotografia como ferramenta auxiliar de avaliação no ensino de química à distância. XVIII Encontro Nacional de Educação Química, 2016. Anais ... Florianópolis/SC: SBQ, 2016, p. 1.

ARANTES, A. P. P.; GEBRAN, R. A. Ensino superior: trajetórias e saberes docentes. Colloquium Humanarum, Presidente Prudente/SP, v. 9, n. 2, 2012, p. 79-91.

ARROIO, A. Formação docente para o ensino superior em química. VII Encontro Nacional de Pesquisa em Educação em Ciências, 2009. Atas... Florianópolis/SC: ABRAPEC, 2009 p. 112.

BARONEZA, J. E.; SILVA, S. O. Uma reflexão sobre a formação de professores para o ensino superior no Brasil. Acta Scientiarum: Human and Social Sciences, v. 29, n. 2, 2007, p. 163168.

BASTOS, A. V. B.; TOURINHO, E. Z.; YAMAMOTO, O. H.; MENANDRO, P. R. M. Formar docentes: em que medida a pós-graduação cumpre esta missão? RAC, Curitiba/PR, v. 15, n. 6, 2011, p. 1152-1160.

BOLZAN, D. P. V.; AUSTRIA, V. C.; LENZ, N. Pedagogia universitária: a aprendizagem docente como um desafio à professoralidade. Acta Scientarium: Education, Maringá/PR, v. 32, n. 1, 2010, p. 119-126.

BORGES, M. C.; AQUINO, O. F. Educação superior no Brasil e as políticas de expansão de vagas do Reuni: avanços e controvérsias. Educação: teoria e prática, Rio Claro/SP, v. 22, n. 39, 2012, p. 117-138.

BORGES, M. D.; ARANHA, J. M.; SABINO, J. A fotografia de natureza como instrumento para educação ambiental. Ciência \& Educação, v. 16, n. 1, 2010, p. 149-161. 
CAMPELO, R. P. M.; MONTEIRO, V. S.; GONTIJO, A. B.; PAES, T. A. S. V.; RODRIGUES, R. L.; SANT'ANNA, E. M. E.; ANTONINI, Y.; RIBEIRO, S. P. Uma nova abordagem do estágio docência para ciências biológicas. RBPG, Brasília/DF, v. 7, n. 14, 2010, p. 507-518.

CASTRO, R. P. Pensando sobre formação docente, subjetividade e experiência de si a partir da escrita de estudantes de Pedagogia. Pro-posições, v. 27, n. 1 (79), 2016, p. 37-55.

CONFORTIN, R. Transitando entre saberes e não saberes da docência no ensino superior. In: FÁVERO; A. A.; TONIETO, C.; ODY, L. C. (Org.). Docência universitária: pressupostos teóricos e perspectivas didáticas. Campinas/SP: Mercado de Letras, 2015, p. 149-169.

CUNHA, M. I. Docência na universidade, cultura e avaliação institucional: saberes silenciados em questão. Revista Brasileira de Educação, v. 11, n. 32, 2006, p. 258-371.

DUBET, F. Qual democratização do ensino superior? Caderno CRH, Salvador/BA, v. 28, n. 74, p. 255-265, mai/ago 2015.

FÁVERO, A. A.; TONIETO, C. Criatividade não é improvisação: crítica a uma concepção equivocada de docência universitária. In: FÁVERO; A. A.; TONIETO, C.; ODY, L. C. (Org.). Docência universitária: pressupostos teóricos e perspectivas didáticas. Campinas/SP: Mercado de Letras, 2015, p. 17-36.

FEITOSA, J. P. A. Construindo o estágio de docência da pós-graduação em química. Química Nova, v. 25, n. 1, 2002, p. 153-158.

FERREIRA, P. F. M.; JUSTI, R. S. Modelagem e o "Fazer Ciência". Química Nova na Escola, n. 28, 2008, p. 32-36.

FLÔR, C. C. Leitura e formação de leitores em aulas de Química no Ensino Médio. Florianópolis; UFSC, 2009, 235f. Tese (Doutorado) - Programa de Pós-Graduação em Educação Científica e Tecnológica, Universidade Federal de Santa Catarina, Florianópolis/SC, 2009.

FRANCISCO JR., W. E. Uma abordagem problematizadora para o ensino de interações intermoleculares e conceitos afins. Química Nova na Escola. n. 29, 2008, p. 2023.

GILMORE, R. Alice no país do quantum: uma alegoria da física quântica. Rio de Janeiro/RJ: Jorge Zahar Ed., 1998. 192 p.

JAPIASSU, H. Interdisciplinaridade e patologia do saber. Rio de Janeiro/RJ: Imago, 1976. $220 \mathrm{p}$.

JOAQUIM, N. F.; BOAS, A. A. V.; CARRIERI, A. de P. Entre o discurso praticado e a realidade percebida no processo de formação docente. Avaliação, v. 17, n.2, p. 503-528, 2012.

JUNGES, K. S.; BEHRENS, M. A. Uma formação pedagógica inovadora como caminho para a construção de saberes docentes no Ensino Superior. Educar em Revista, n. 59, 2016, p. 211-229.

LEVINSKY, E. Z.; CORREA, C. T.; MATTOS, M. Docência universitária: planejamento da disciplina e organização da aula. In: FÁVERO; A. A.; TONIETO, C.; ODY, L. C. (Org.). Docência universitária: pressupostos teóricos e perspectivas didáticas. 1. ed. Campinas: Mercado de Letras, 2015, capítulo 10, p. 207-222. 
MELO, M. R.; LIMA NETO, E. G. L. Dificuldades de ensino e aprendizagem dos modelos atômicos em química. Química Nova na Escola. v. 35, n. 2, 2013, p. 112-122.

MENDONÇA, A. W. P. C. A universidade no Brasil. Revista Brasileira de Educação, n. 14, 2000.

MONFORTE, J. S. S. A subjetividade da imagem na construção do discurso verbo-visual da HQ: uma análise do "Dom Quixote das crianças" em quadrinhos. In: SAPPIL, IX, 2018, Niterói.

PIMENTEL, V.; MOTA, D. D. C. F.; KIMURA, M. Reflexões sobre o preparo para a docência na pós-graduação em enfermagem. Revista Escola de Enfermagem USP, v. 21, n. 1, 2007, p. 161-164.

QUEIROZ, S. L. A linguagem escrita nos cursos de graduação em química. Química Nova, v. 24, n. 1, 2001, p. 143-146.

RAUPP, D.; SERRANO, A.; MOREIRA, M. A. Desenvolvendo habilidades visuoespaciais: uso de software de construção de modelos moleculares no ensino de isomeria geométrica em química. Experiências em Ensino de Ciências, v.4, n. 1, 2009, p. 65-78.

ROJAS-BETANCUR, H. M. Docência e formação científica universitária. Revista Internacional de Investigación em Educación, v. 4, n. 7, 2011, p. 121-136.

SCHÖN, D. A. Formar Professores como Profissionais Reflexivos. In: NÓVOA, A. Os professores e a sua Formação (Org.). Lisboa: Dom Quixote, 1995, p. 75-91.

SOLÁZ-PORTOLÉS, J. J. Sobre cómo el conocimiento científico intenta aproximarse a la realidad. Revista Brasileira de Ensino de Física. v.34, n. 1, 2012, p.1308-1 - 1308-5.

TARDIF, M. Saberes docentes e formação profissional. Petrópolis/RJ: Vozes, 2014. 328 p. . Saberes profissionais dos professores e conhecimentos universitários. Revista Brasileira de Educação, n. 13, 2000, p. 5-24.

WALL, M. L.; PRADO, M. L.; CARRARO, T. E. A experiência de realizar um Estágio Docência aplicando metodologias ativas. Acta Paulista de Enfermagem, v. 21, n. 3, 2008, p. 515-519.

WARTHA, E. J.; REZENDE, D. B. Os níveis de representação no ensino de química e as categorias da semiótica de Peirce. Investigações em Ensino de Ciências, v. 16, n. 2, 2011, p.275-290.

\section{Agradecimentos}

Agradecemos à CAPES pela concessão da bolsa de mestrado e aos participantes da pesquisa.

$* * *$

Recebido: 31/01/2019

Aprovado: 10/07/2020 